\title{
Voter Beliefs, Electoral Concerns and Undocumented Migration
}

\author{
Ruxanda Berlinschi ${ }^{1,2}$, Mara Pasquamaria Squicciarini ${ }^{2,3}$ \\ ${ }^{1}$ Department of Economics, HUBrussel (HUB), Brussels, Belgium \\ ${ }^{2}$ LICOS, Centre for Institutions and Economic Performance, Department of Economics, \\ University of Leuven, Leuven, Belgium \\ ${ }^{3}$ FWO-Research Foundation Flanders, Brussels, Belgium \\ Email: ruxanda.berlinschi@hubrussel.be, mara.squicciarini@kuleuven.be
}

Received July 25 ${ }^{\text {th }}$, 2013; revised August 29 ${ }^{\text {th }}$, 2013; accepted September $13^{\text {th }}, 2013$

\begin{abstract}
Copyright (C) 2013 Ruxanda Berlinschi, Mara Pasquamaria Squicciarini. This is an open access article distributed under the Creative Commons Attribution License, which permits unrestricted use, distribution, and reproduction in any medium, provided the original work is properly cited.
\end{abstract}

\begin{abstract}
If voters underestimate the benefits that immigrants bring to their country, policy makers need to campaign for suboptimal migration levels in order to win elections. Once in power, they face a trade-off between keeping electoral promises by restricting immigration and stimulating the economy by favoring immigration. One solution to this trade-off may be maintaining high barriers to legal migration, while keeping a blind eye on undocumented migration.
\end{abstract}

Keywords: Immigration; Biased Beliefs; Electoral Concerns

\section{Introduction}

As immigration to Western countries has been increasing in the past decades, its effects on host countries have been observed, analyzed and discussed at various levels, from academic journals, to policy reports, press stories and everyday conversations. In these ongoing debates, a gap seems to emerge between the conclusions of scientific studies regarding the effects of immigration and public perceptions of these same effects.

Scientific studies give a broadly positive picture of the overall impact of immigration on the economy and society. Immigrants are good for the economy because they stimulate innovation (Hunt \& Gauthier-Loiselle, 2008), productivity (Chellaraj et al., 2008), and growth (Ortega \& Peri, 2009). Increasing South-North migration could lead to huge income gains, a significant part of which would be reaped by host countries (Anderson \& Winters, 2008; Clemens, 2011). Immigrants have a small positive impact on public finances (Auerbach \& Oreopoulos, 1999; Lee \& Miller, 2000), i.e. on average, their tax contributions exceed the benefits they receive. While immigration does sometimes depress wages of non-qualified workers in destination countries, these effects are small and negligible compared to the overall gains from labor mobility (Friedberg \& Hunt, 1995; Card, 2001; Clemens, 2011). Migration does lead to greater religious and cultural heterogeneity in the host country, and while this undermines trust and social solidarity in the short run (Putnam, 2007), it brings social benefits in the long run.

Public opinion about immigration is generally less positive, as witnessed by the rise of anti-immigration parties in many Western countries and the consistent presence of immigration among the main public policy concerns in opinion polls ${ }^{1}$. People's negative attitudes towards migration have two main dimensions: economic and cultural (Mayda, 2006; Scheve \&

\footnotetext{
${ }^{1}$ Ex: Eurobarometer (2006, 2013)
}

Slaughter, 2001; O’Rourke \& Sinott, 2006). Many natives believe that migrants are stealing their jobs, putting downwards pressure on their wages and abusing the social system. Few natives are aware of immigrants' positive impact on innovation, trade, entrepreneurship and job creation. Many natives perceive immigrants as a threat to their culture, values and security and are not aware of the long term social benefits of inter-ethnic interaction.

This divergence between scientific studies and public opinion could be explained by the fact that the benefits of migration are widespread and diffuse, while its costs, such as an incident with a member of a foreign community, are local and concentrated, and therefore more visible. Moreover, specific negative stories are more likely to catch media and public attention than diffuse medium term benefits (McCluskey \& Swinnen, 2004; Swinnen \& Heinz, 2013).

Policy makers are informed about both academic and public opinion on a certain issue. In order to win elections, they need to promise policies that are appealing to the electorate, i.e. restricted immigration. In order to stimulate the economy, they need to implement policies that would bring economic and social benefits, i.e. more open immigration. Elected politicians therefore face the trade-off between being perceived as promise-keeping and being perceived as having stimulated economic growth, both of which affect the probability to be re-elected. One possible solution to this trade-off is to keep restrictions to legal migration and tolerate a certain level of undocumented migration. This solution may work if voters believe that legal migration flows are chosen by the authorities to a larger extent than undocumented migration flows. We formalize this argument with a simple political-economy model.

This note contributes to a recent strand of the political economy of migration literature, which hypothesizes that high numbers of undocumented migrants are deliberately tolerated by some governments, for economic, political and electoral 
reasons (Hillman \& Weiss, 1999; Fasani, 2009; Facchini \& Testa, 2010; Berlinschi \& Squicciarini, 2011). By focusing on politicians' electoral concerns as an explanation for illegal immigration, this paper is closest in line with Facchini and Testa (2010). While in their paper undocumented immigration is driven by voters' imperfect information about the politician's type, in our paper it is driven by voters' imperfect information about the impact of immigration.

\section{Theoretical Framework}

Consider an economy populated by $N$ natives, indexed by $i$, who elect a politician for implementing a certain migration policy. Migration policy is defined as a couple $(M, I)$ where $M$ is the number of legal and $I$ the number of illegal migrants allowed to participate in the economy. Assume that there exists an optimal total migration level $M_{i}^{*} \geq 0$ for each voter $i$, and that for a given total number of migrants, natives' utility is decreasing with the share of illegal migrants ${ }^{2}$. We model these assumptions by assigning the following reduced-form utility function to native $i$ :

$$
U_{i}(M, I)=c-\left(M+I-M_{i}^{*}\right)^{2}-\mu I^{2},
$$

where $c$ is a constant and $\mu \geq 0$ is the magnitude of the welfare loss associated with migrants' illegal status. This utility function is maximized at $I=0$ and $M=M_{i}^{*}$.

Let $i=m$ be the median voter, whose utility function:

$$
U_{m}(M, I)=c-\left(M+I-M^{*}\right)^{2}-\mu I^{2},
$$

is maximized at $I=0$ and $M=M^{*}$.

Assume that voters underestimate the migration level which maximizes their utility. This can be modeled by assuming that the anticipated utility of native $i$, i.e. before migration policy is implemented, is given by:

$$
U_{i}^{A}(M, I)=c-\left(M+I-M_{i}^{A}\right)^{2}-\mu I^{2},
$$

with $M_{i}^{A}<M_{i}^{*}$ for all $i$.

Denote by $M^{C}$ median voter's anticipated optimal migration level with $M^{*}>M^{C}$.

Assume that incumbent politicians are judged both on their achievements (voters' welfare at the end of their mandate) and on their credibility (the extent to which they have kept their electoral promises).

Consider the following three-stage game, $t \in\{1,2,3\}$. In stage 1 , elections take place. In this stage, all politicians are challengers competing on migration policies. Under majority voting, the policy winning the political contest will be the one closest to median voter's preferences, i.e. $\left(M^{C}, 0\right)$. In stage 2 , the elected politician implements a certain migration policy $(M$, $I)$ which may differ from the electoral promise $\left(M^{C}, 0\right)$. At the end of this stage, voters observe their welfare, as well as the gaps between the electoral promise and the implemented policies, i.e. $M-M^{C}$ and $I$. In stage 3, a second election takes place. In this election the incumbent politician competes with a challenger. The probability for the incumbent to be re-elected depends positively on voters' welfare and negatively on the gap

${ }^{2}$ This assumption is supported by many public opinion surveys, such as EuroBarometer. This may be due to illegal migrants being employed in the black economy, paying fewer taxes and social security contributions being on average less skilled and considered more likely to engage in criminal activities. between electoral promises and implemented policies.

Should deviations in legal and undocumented migration induce the same credibility loss for the policy maker? We argue that deviations in illegal migration should induce a smaller loss in credibility. While legal migrants have a visa or a residence permit provided by the authorities, undocumented migrants are by definition not allowed to reside in the country. Therefore legal migration flows should be perceived as being a result of authorities' intention, to a larger extent than undocumented migration flows.

We can model these ideas by assuming that the probability for the incumbent to be re-elected is an increasing function of $E$, where $E$ given by:

$$
E \equiv c-\left(M+I-M^{*}\right)^{2}-\mu I^{2}-\gamma\left(M-M^{C}+\lambda I\right)^{2}
$$

The first three terms of $E$ represent median voter's welfare at the end of period 2, as a function of implemented migration policies. The last term represents deviations from electoral promises. The term $\gamma \geq 0$ represents the weight of the credibility loss on the probability of being re-elected. The term $1>\lambda \geq 0$ represents the relatively lower cost of deviations in undocumented migration levels.

Let us now derive the two endogenous variables of the model, i.e. migration policies implemented in period 2. The policy maker will implement the policies that maximize re-election probability, i.e. he will maximize $E$ with respect to $M$ and $I$. This simple optimization problem leads to the following result.

Result: The migration policy $\left(M^{O}, I^{O}\right)$ implemented by the incumbent politician is given by:

$$
\begin{aligned}
M^{O} & =\frac{\gamma[\mu+(1-\lambda)]}{\gamma(1-\lambda)^{2}+\mu(1+\gamma)} M^{C}+\frac{\mu-\gamma \lambda(1-\lambda)}{\gamma(1-\lambda)^{2}+\mu(1+\gamma)} \\
I^{O} & =\frac{\gamma(1-\lambda)}{\gamma(1-\lambda)^{2}+\mu(1+\gamma)}\left[M^{*}-M^{C}\right] .
\end{aligned}
$$

In order to maximize re-election probability, the politician should implement a legal migration level $M^{O}$ equal to a convex combination between the optimal and campaigned migration levels $M^{*}$ and $M^{C}$, and a strictly positive illegal migration level $I^{O}$. The deviations between promised and implemented migration levels arise from voters' biased beliefs about the impact of migration. From (5) and (6), it is easy to check that if the median voter has correct beliefs about the welfare maximizing policy, then the politician does not deviate from electoral promises and chooses zero undocumented migration, i.e. if $M^{C}=M^{*}$, then $M^{O}=M^{C}=M^{*}$ and $I^{O}=0$. From (6), we can also see that if the credibility loss suffered by the politician is the same for deviations in legal and undocumented migration levels, no illegal migration will be induced, i.e. if $\lambda=1$, then $I^{O}=0$. The level of illegal migration $I^{O}$ is decreasing in the welfare cost associated with illegality $\mu$ and in the credibility parameter $\lambda$.

Some level of undocumented immigration may thus be intentionally tolerated by policy makers when the following conditions are satisfied: voters underestimate the optimal number of immigrants for their country, politicians are electorally compensated for stimulating the economy and for keeping electoral promises, and undocumented migration is perceived to be less controllable than regular migration. 


\section{Conclusion}

Many Western voters seem to underestimate the benefits that immigrants bring to their country. Policy makers concerned with winning elections therefore do not campaign for reducing immigration barriers, even though such policies could bring huge economic benefits according to scientific studies. Once in power, policy makers face the trade-off between stimulating the economy by increasing immigration, and being perceived as keeping electoral promises by restricting immigration. The solution to this trade-off may be maintaining strong barriers to legal migration, while turning a blind eye on undocumented migration. Even though undocumented immigrants may bring fewer economic benefits, as they only work in some specific sectors and pay less taxes, such a strategy may allow policy makers to help some economic sectors and in the same time avoid being perceived as too immigration-friendly, since by definition, undocumented migrants are not allowed to reside in the country. This argument may partly explain why some western governments have been silently allowing hundreds of thousands of undocumented migrants to participate in their economies, while keeping strong restrictions on legal migration channels.

\section{Acknowledgements}

We thank A. Ariu, G. De Luca, and J. Fidrmuc for their comments and suggestions. M.P.S. gratefully acknowledges financial support from FWO-Flanders.

\section{REFERENCES}

Anderson, K., \& Winters, L. A. (2008). The challenge of reducing international trade and migration barriers. CEPR Discussion Paper 6760 .

Auerbach, A. J., \& Oreopoulos, P. (1999). Analyzing the fiscal impact of US immigration. American Economic Review, 89, 176-180. http://dx.doi.org/10.1257/aer.89.2.176

Berlinschi, R., \& Squicciarini, M. P. (2011). On the political economy of illegal immigration. Working paper.

Card, D. (2001). Immigrant inflows, native outflows and the local labor market impacts of higher immigration. Journal of Labour Economics, 19, 22-64. http://dx.doi.org/10.1086/209979

Chellaraj, G., Maskus, K. E., \& Mattoo, A. (2008). The contribution of skilled immigration and international graduate students to US innovation. Review of International Economics, 16, 444-462. http://dx.doi.org/10.1111/j.1467-9396.2007.00714.x

Clemens, M. (2011). Economics and emigration: Trillion-dollar bills on the sidewalk? Journal of Economic Perspectives, 25, 83-106. http://dx.doi.org/10.1257/jep.25.3.83

European Commision (2006). Eurobarometer Survey. http://ec.europa.eu/public_opinion/index_en.htm

European Commision (2013). Eurobarometer Survey. http://ec.europa.eu/public_opinion/index_en.htm

Facchini, G., \& Testa, C. (2010). The rhetoric of closed borders: Quotas, lax enforcement and illegal migration. NORFACE MIGRATION Discussion Paper No. 2010-1.

Fasani, F. (2009). Deporting undocumented immigrants. The role of labour demand shocks. Mimeo: University College London.

Friedberg, R. M., \& Hunt, J. (1995). The impact of immigrants on host country wages, employment and growth. Journal of Economic Perspectives, 9, 23-44. http://dx.doi.org/10.1257/jep.9.2.23

Hillmann, A. L., \& Weiss, A. (1999). A theory of permissible illegal immigration. European Journal of Political Economy, 15, 585-604. http://dx.doi.org/10.1016/S0176-2680(99)00039-7

Hunt, J., \& Gauthier-Lauselle, M. (2008). How much does immigration boost innovation? NBER Working Paper No. 14312.

Lee, R., \& Miller, T. (2000). Immigration, social security, and broader fiscal impacts. American Economic Review, 90, 350-354. http://dx.doi.org/10.1257/aer.90.2.350

Mayda, A. M. (2006). Who is against immigration? A cross country investigation of individual attitudes towards immigrants. Review of Economics and Statistics, 88, 510-530. http://dx.doi.org/10.1162/rest.88.3.510

McCluskey, J., \& Swinnen, J. (2004). Political economy of the media and consumer perceptions of biotechnology. American Journal of Agricultural Economics, 86, 1230-1237. http://dx.doi.org/10.1111/j.0002-9092.2004.00670.x

O’Rourke, K., \& Sinnott, R. (2006). The determinants of individual attitudes towards immigration. European Journal of Political Economy, 22, 838-861. http://dx.doi.org/10.1016/j.ejpoleco.2005.10.005

Ortega, F., \& Peri, G. (2009) The causes and effects of international labor mobility: Evidence from OECD countries 1980-2005. Human Development Research Paper 6, New York: United Nations Development Program (UNDP).

Putnam, R. (2007). E pluribus unum: Diversity and community in the twenty-first century. Scandinavian Political Studies, 30, 137-174. http://dx.doi.org/10.1016/j.ejpoleco.2005.10.005

Scheve, K. F., \& Slaughter, M. J. (2001). Labor-market competition andindividual preferences over immigration policy. Review of Economics and Statistics, 83, 133-145.

http://dx.doi.org/10.1162/003465301750160108

Swinnen, J., \& Heinz, M. (2013). Media bias in economic news: A factor 20. LICOS DP 330. 